\title{
How to Mitigate Mercury Pollution in Tanzania
}

\author{
Peter W. U. Appel ${ }^{1}$, Leoncio Na-Oy ${ }^{2}$ \\ ${ }^{1}$ Department of Petrology and Ore Geology, Geological Survey of Denmark and Greenland, Copenhagen, Denmark; ${ }^{2}$ Benguet Fed- \\ eration of Small-Scale Miners, Baguio, Philippines. \\ Email: pa@geus.dk
}

Received February 22 $2^{\text {nd }}, 2013$; revised March 24 ${ }^{\text {th }}, 2013$; accepted May $21^{\text {st }}, 2013$

Copyright (C 2013 Peter W. U. Appel, Leoncio Na-Oy. This is an open access article distributed under the Creative Commons Attribution License, which permits unrestricted use, distribution, and reproduction in any medium, provided the original work is properly cited.

\begin{abstract}
Mercury pollution from small-scale gold mining poses a serious threat to the global and local environment. Recycling of mercury for small-scale miners has been introduced over decades in Tanzania with little success. The environmentally benign borax gold extraction method invented more than thirty years ago in the Philippines and presently used by more than thirty thousand Philippine miners has proved to work on the gold ores in Chunya and Singida gold districts of Tanzania. By using borax instead of mercury the miners reduce the risk of polluting the environment and spoil their health for generations. The most convincing argument for the miners to change to borax is that they can increase their gold recovery up to fifty percent without need for investing in new equipment and without much more work on processing.
\end{abstract}

Keywords: Small-Scale Mining; Mercury; Borax

\section{Introduction}

Gold has been mined in Tanzania for decades both by mining companies and by small-scale miners. Smallscale gold mining has gained considerable momentum over the last decades due to the high price of gold. In Tanzania several hundred thousand people depend on small-scale gold mining. It is carried out in large parts of the country from Lake Victoria region through Singida and Chunya regions to Mpanda-Lake Tanganyika area [1].

A large proportion of small-scale gold miners are migrant workers who work at one location until a rumor spreads of a new promising gold discovery. This then creates occasional gold rushes. Londoni near Manyoni was a sleepy village with a few hundred inhabitants depending on farming. One day gold was discovered and in no time more than ten thousand people invaded the area. Some of them were small-scale miners while others were workers providing food, beverages and sex. This turned life at Londoni upside down. Other mining sites are more long lived e.g. Itumbi near Chunya where gold mining has been carried out for decades [2].

Migrant miners and stationary miners use slightly different working methods. Migrant workers extract their gold using simple generally very inefficient equipment whereas stationary miners try to improve their gold extraction method continuously.

Over the last several decades many attempts have been made to improve the living conditions of the small-scale miners, mainly focused on finding ways to increase productivity and reduce the negative environmental impact of the gold mining. A particular focus has been on reducing the mercury pollution of the environment, thereby reducing the serious health risks of the population.

This paper provides a roadmap for replacing mercury gold extraction (amalgamation) with the borax gold method [3] which is not only is environmentally benign but will increase gold extraction for the miners significantly.

This paper i a contribution to the IGCP/SIDA 594 programme.

\section{Amalgamation}

The vast majority of small-scale gold miners use mercury for extracting the yellow metal. The first step in mining is sinking shafts and digging tunnels. This is mostly done with as little technical equipment as possible. Hammer and chisels are the essential tools, and sometimes dynamite is used for breaking the rocks. The shafts are sunk to more than $60 \mathrm{~m}$ below the surface. Tunnels are dug 
from the shafts in order to follow the gold veins. The tunnels are up to tens of meters long. Roof and wall supports are rarely constructed.

When gold ore is broken and hoisted up to the surface, it is crushed. This is mostly done manually. Next, the $\mathrm{cm}$-sized bits of gold ore are ground in ball or rod mills. After milling the heavy minerals including gold are separated from the light minerals. This is done gravitationally in various ways with simple homemade equipment.

When a heavy mineral concentrate is produced, mercury is added, and thoroughly mixed with the heavy minerals. Mercury forms an amalgam with the gold. The amalgam is separated from the heavy minerals and heated over an open fire whereby mercury evaporates and the gold is left behind. Not all the mercury is collected and the runoff collects in the tailings.

In Itumbi and Londoni samples of milled ore and their heavy mineral concentrates were analyzed for gold in order to determine the efficiency of the processing (Table 1). The wide range in enrichment ratio of the different samples depicts the differences in efficiency form one plant to the next.

Table 1. Gold content in milled ore (RS-X milled) and heavy mineral concentrates (RS-X concentrate), showing enrichment factors during concentration of heavy minerals.

\begin{tabular}{|c|c|c|}
\hline & Au g/ton & Enrichment \\
\hline RS-1 milled & 3.64 & \\
\hline RS-2A milled & 19.6 & \\
\hline RS-2B milled & 11 & \\
\hline RS-2C milled & 6.8 & \\
\hline RS-3 milled & 3.72 & \\
\hline RS-4 milled & 48.1 & \\
\hline RS-5 milled & 2.74 & \\
\hline RS-7 milled & 10.5 & \\
\hline RS-13 milled & 1.91 & \\
\hline RS-1 concentrate & 43.6 & 12 \\
\hline RS-2A concentrate & 736 & 38 \\
\hline RS-2B concentrate & 244 & 22 \\
\hline RS-2C concentrate & 316 & 46 \\
\hline RS-3 concentrate & 94.2 & 25 \\
\hline RS-4 concentrate & 346 & 7 \\
\hline RS-5 concentrate & 9.82 & 4 \\
\hline RS-7 concentrate & 93.6 & 9 \\
\hline RS-13 concentrate & 19.1 & 10 \\
\hline
\end{tabular}

\section{Reprocessing of Gold Ore}

The small-scale miners believe that their milling is not efficient and further milling may liberate more gold. After first gold extraction the tailings are re-milled and re-processed and with each processing more and more mercury is carried over to the tailings. Re-processing may be done up to ten times.

Table 2 shows gold contents in tailings (OT-XX) which are not regarded as exhausted and indeed these tailings have high gold contents. Table 2 also shows gold contents in so-called exhausted tailings (FW-XX). The high gold content in the so-called exhausted tailings cannot be ascribed to incomplete milling, since the tailings have been milled up to ten times. The culprit is the use of mercury for extracting gold. When mercury is milled the repeated beating by hard metal rods or balls it causes the formation of mercury flour (Figure 1). These are less than millimeter sized globules of mercury that have lost their ability to coalesce and cannot be recovered by the miners. Neither can the gold amalgamated in the mercury flour be captured. The tailings which are still to be processed (OT-XX) thus contain mercury. The exhausted tailings (FW-XX) do not contain mercury, but high amounts of gold (Table 2). The reason being that the mercury in those tailings has had time to evaporate and left the gold behind.

Mercury is not only released during burning of amalgam, but also from the numerous tailings littering the mining communities.

Table 2. Gold and mercury content in active tailings (OT$\mathrm{XX}$ ) and tailings regarded as exhausted (FW-XX).

\begin{tabular}{cccc}
\hline & & Gold g/t & Mercury g/t \\
\hline OT-1A & Itumbi & 6.67 & 1.94 \\
OT-1B & Itumbi & 6.85 & 2.15 \\
OT-1C & Itumbi & 5.2 & 2.21 \\
OT-2A & Itumbi & 7.51 & 0.58 \\
OT-2B & Itumbi & 5.05 & $<0.01$ \\
OT-2C & Itumbi & 9.02 & $<0.01$ \\
FW-1 & Itumbi & 12.2 & $<0.01$ \\
FW-2 & Itumbi & 9.84 & $<0.01$ \\
FW-3 & Itumbi & 12.6 & $<0.01$ \\
FW-4a & Londoni & 4.2 & $<0.01$ \\
FW-4b & Londoni & 32 & $<0.01$ \\
FW-6 & Londoni & 3.24 & $<0.01$ \\
FW-7 & Londoni & 1.6 & $<0.01$ \\
FW-8 & Londoni & 4.83 & $<0.01$ \\
\hline
\end{tabular}




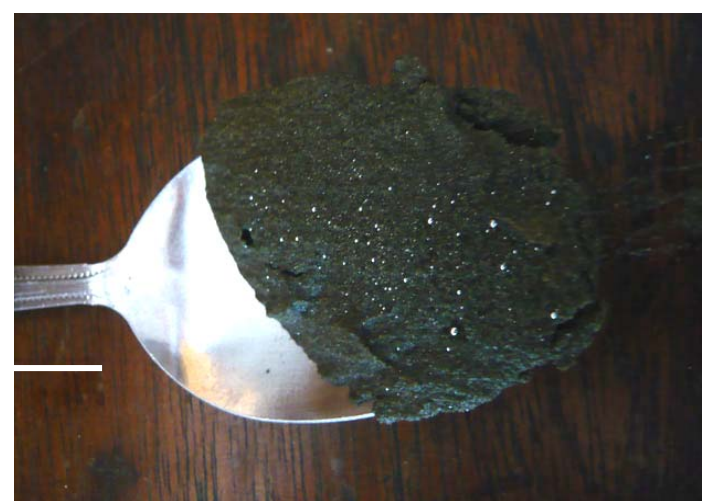

Figure 1. Mercury flour in tailings. Scale $1 \mathrm{~cm}$.

\section{Mercury in the Environment}

In order to get a first impression of the effects of mercury pollution on the environment, a pilot study on soil and air was carried out in Itumbi and Londoni. Soil samples were collected in and around the villages, but not in immediate vicinity of the working areas. The results are shown in Table 3 [2]. It is obvious that soil in and around Itumbi and Londoni is heavily polluted with mercury. It should be noted that soil as far as $10 \mathrm{~km}$ from Londoni and any other small-scale mining sites is polluted; indicating that mercury pollution from mining has regional impact on the environment and health of the population of Tanzania.

Test measurements of mercury vapor in air were carried out in Itumbi and Londoni (Table 4). The danger level of mercury in ambient air for working 6 hours in industry is $1 \mu \mathrm{g} / \mathrm{m}^{4}$. It must be noted that the figures in Itumbi and Londoni show the average of 24 hours of measurements indicating the amount of mercury which is inhaled day and night by the population of Itumbi and Londoni [4]. The high mercury contents in the atmosphere also indicate that the mercury will be distributed over large areas and not only in small mining communities.

\section{Ways to Mitigate Mercury Pollution from Small-Scale Mining}

Small-scale gold mining is here to stay. It puts food on the table for millions of people, but it causes local and global mercury pollution. The Tanzanian government decades ago banned import and sale of mercury, but unfortunately mercury is still easily available all over the country. The solution is therefore to teach small-scale miners better and environmentally safe working methods. Several donor organisations have over the years supported projects trying to find alternatives to use of mercury or to reduce mercury consumption.

A very popular and promising invention to reduce mercury pollution is the retort, invented decades ago in
Table 3. Mercury content in soils at and near processing sites.

\begin{tabular}{lc}
\hline Soil sample no. and location & Hg g/ton \\
\hline SS-.1 In Itumbi village & 3.54 \\
SS-2 In Itumbi village & 0.29 \\
SS-3 In Itumbi village & 0.57 \\
SS-4 In Itumbi village & 0.76 \\
SS-5 3.5 km from Itumbi village & 1.1 \\
SS-6 7 km from Itumbi village & 0.24 \\
SS-7 A km outside Londoni village & 0.09 \\
SS-8 A km outside Londoni village & 0,07 \\
SS-9 In Londoni village & 0.77 \\
SS-10 In Londoni village & 0.87 \\
SS-11 In Londoni village & 0.31 \\
SS-12 In Londoni village & 0.22 \\
SS-13 In Londoni village & 0.69 \\
SS-14 In Londoni village & 0.83 \\
SS-15 10 km from Londoni village & 2.9 \\
\hline
\end{tabular}

Table 4. Mercury in ambient air in Itumbi and Londoni small-scale mining sites.

\begin{tabular}{cc}
\hline Itumbi & $0.32-0.44 \mu \mathrm{g} / \mathrm{m}^{3}$ \\
\hline Londoni & $1.35-1.87 \mu \mathrm{g} / \mathrm{m}^{3}$ \\
Global background southern hemisphere & $1.2 \mathrm{ng} / \mathrm{m}^{3}$ \\
\hline
\end{tabular}

South America. In its simplest form it consists of a few pieces of plumbing tubes whereby the miners recycle mercury thereby reducing release of mercury to the environment by up to $90 \%$. The amalgam is placed in a small cup of iron which is attached to a bent iron tube. The cup holding the amalgam is placed in a charcoal burner and the tube ends in a bowl of water (Figure 2). After prolonged heating mercury evaporates from the amalgam and condenses in the iron tube. Drops of mercury accumulate in a bowl of water. When no more drops of mercury runs into the water the cooking is finished. After proper cooling the retort can be opened and the gold removed from the cup. The gold is not pure, but holds $5 \%$ to $10 \%$ mercury. The gold is sold to gold dealers who burn off the remaining mercury.

The retort looks as a win-win solution. Less pollution-less expenses for buying mercury. Recently, Jønsson et al. (2013) [1] carried out an investigation of projects carried out over the last decades in Rwamagasa area 


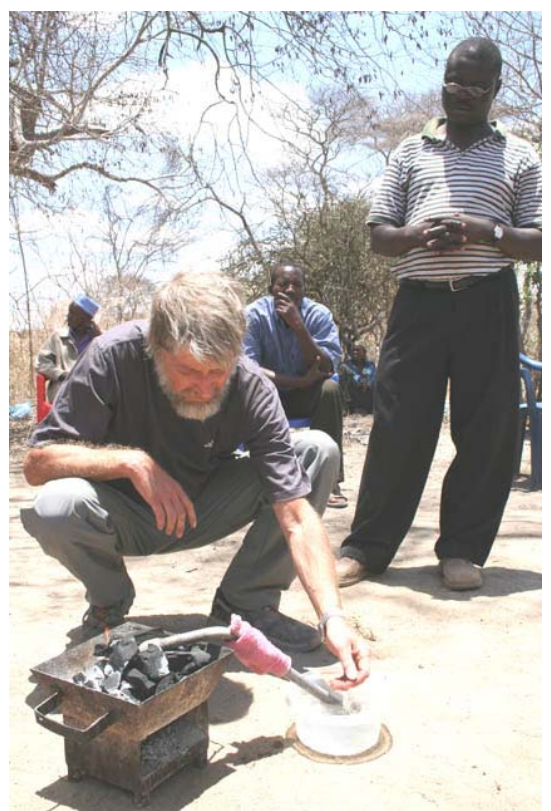

Figure 2. Retort for distillation of mercury.

North-western Tanzania. Up to 2007, several donors had carried out 220 training courses for 1430 villagers.

98 retorts were reportedly used and 250 miners were reportedly willing to use retorts. In 2011 the area was visited by Jønsson et al. (2013) who found only one retort and that was unused. Jønsson et al. (2013) suggested the following explanations for the lack of success.

- Lack of follow up on the teaching and training.

- The gold is often brown after retorting.

- Retorting takes too long time.

- The burning requires much charcoal.

\section{Borax Method}

More than thirty years ago a group of small-scale gold miners in the Philippines replaced mercury with borax for gold extraction. It quickly caught on in the local communities and soon well over 15,000 miners used bo$\operatorname{rax}[3]$.

Borax based gold extraction is an environmentally benign method which does not require investment in new equipment for the miners. The process is as follows: The mining, crushing, milling and concentration of the heavy minerals are the same as used for gold extraction with mercury. The final step of heavy mineral concentration does require some training and skill. It is necessary to produce a gold concentrate with very high concentration of gold. When a good gold concentrate has been prepared it is mixed with borax in a small piece of plastic and placed in a clay bowl with a few pieces of ignited charcoal [5]. The temperature of the mixture is increased by vigorous blowing. After 5 to 10 minutes depending on the gold concentration, the heavy mineral concentrate
Table 5. Recovery of gold using amalgam versus borax.

\begin{tabular}{ccc}
\hline & Amalgamation & Borax \\
\hline $\begin{array}{c}\text { Average recovery pr sack } \\
\text { from 7 sacks of gold ore }\end{array}$ & $1.2 \mathrm{~g}$ Au pr sack & $3.2 \mathrm{~g}$ Au pr sack \\
Total recovery from 7 sacks & 8.4 g gold & $22.4 \mathrm{~g}$ gold \\
\hline
\end{tabular}

melts. Gold drops coalesce on the bottom of the clay bowl to form a small pellet of pure gold.

The borax process has one limitation. It only works on ore deposits with visible gold, whereas mercury also works on gold ores without visible gold. The reason for this puzzle is the subject of a research project presently being carried out in Indonesia.

\section{How to Convince Small-Scale Miners to Adopt the Borax Method}

It is often difficult to convince miners who have used amalgamation for decades to change to another method. A Danish financed teaching and training project in the Philippines developed a way to convince miners to use borax instead of mercury [5].

The teaching team explains the miners that by using borax they not only avoid mercury pollution of the environment and serious health problems for themselves and their children. They also increase their gold recovery by up to fifty per cent. The latter argument sounds good, but the team has to prove it to the miners. The reason that borax method extracts more gold than mercury is that in the latter process mercury flour captures large amounts of gold which cannot be recovered by the miners.

The teacher asks the local miners to process a sack of gold ore with their conventional amalgamation method. The recovered gold is weighed. The teacher grabs another sack of gold ore and processes it using borax. The recovered gold is weighed. Since gold is not evenly distributed the process is carried out eight to ten times and the total amount of gold recovered by the two methods is weighed. An example of such a session carried out in Northern Philippines is shown in Table 5. When confronted with the increased gold recovery most miners are convinced that the borax method has significant advantages.

\section{REFERENCES}

[1] J. B. Jønsson, E. Charles and P. Kalvig, “Toxic Mercury versus Appropriate Technology: Artisanal Gold Miners' Retort Aversion,” Resources Policy, Vol. 38, No. 1, 2013, pp. 60-67. doi:10.1016/j.resourpol.2012.09.001

[2] J. Tychsen and P. W. U. Appel, "Enhancing Environmental Quality through Improved Gold Recovery in Artisan and Small-Scale Gold Mining in Tanzania," Report to National Environmental Management Council, 2010, 
59 Pages.

[3] P. W. U. Appel and L. Na-Oy, "The Borax Method of Gold Extraction for Small-Scale Miners,” Journal of Health and Pollution, Vol. 2, No. 3, 2011, pp. 5-10.

[4] E. M. Thaysen, P. W. U. Appel, H. Skov, G. Asmund and M. E. Goodsite, "Mercury in Ambient Air, Soil and
Maize from Small-Scale Mining Communities in Tanzania,” Poster at SEGH Meeting in Galway, Conference Schedule and Abstracts, 2010, p. 135.

[5] Educational Video Demonstrating the Borax Gold Extraction Process. http://youtu.be/X6Sawj0HyF0 